\title{
A rare cause of benign retroperitoneal mass mimicking adnexial malignancy in a postmenopausal woman: retroperitoneal fibroma
}

\author{
Yasam Kemal Akpak ${ }^{1 *}$, Ozgur Dandin², Ismet Gun ${ }^{3}$, Nuri Kaya ${ }^{3}$ and Vedat Atay ${ }^{3}$ \\ *Correspondence: yasamaster@gmail.com

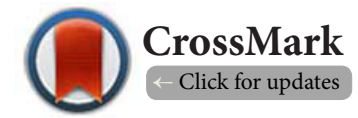 \\ ${ }^{1}$ Ankara Mevki Military Hospital, Department of Obstetrics and Gynecology, Ankara, Turkey. \\ ${ }^{2}$ Bursa Military Hospital, Department of General Surgery, Bursa, Turkey. \\ ${ }^{3}$ Gulhane Military Medical Academy, Haydarpasa Training Hospital, Department of Obstetrics and Gynecology, Istanbul, Turkey.
}

\section{Correspondence}

We read with great interest the article by $\mathrm{G}$ Bassi et al., [1] in which the authors presented a case named "An incidental retroperitoneal solitary fibrous tumor". They mentioned about the clinicopathological characteristics of retroperitoneal solitary fibrous tumor and analyse the diagnosis of retroperitoneal fibrosis. Unfortunately, there are only a few cases of retroperitoneal fibroma reported in the literature. When we search "retroperitoneal fibroma" in PubMed we found only five literatures in english about this rare condition. The total number of reported cases has been fewer than thirteen. Therefore there is limited information about the retroperitoneal fibromas. Fibromas are stromal tumours composed of spindle, oval or round collagen-producing cells that resemble fibroblasts [2]. Herein, we present a patient with pelvic retroperitoneal fibroma which was confirmed histopathologically following surgery. Imaging findings of the tumor mimicked an adnexial mass preoperatively.

A 54-year-old postmenopausal multiparous woman presented us with a complaint of lower abdominal pain, dyspareunia and urinary retention for 3 years. The patient had a history of total abdominal hysterectomy operation 16 years ago. A solid, movable mass was noted in the middle and left lower quadrant of abdomen by abdominopelvic examination. Transvaginal ultrasonography revealed a smooth surfaced solid tumoral mass with calcific degeneration measuring $86 \times 82 \times 88 \mathrm{~mm}$ located in the middle region near the vagına cuff, occupying the left adnexial area (Figure 1A). We did not see ureteral obstruction or ectasia of renal pelvis by abdominal ultrasonography. Laboratory examinations including tumor markers (AFP, CA 125, CEA, CA199, CA 15-3) were unremarkable. Pelvic magnetic resonance imaging demonstrated about $8 \times 8 \mathrm{~cm}$ in size pelvic solid mass with heterogeneous internal structure, showing no significant enhancement, located in the middle and left adnexial region (Figures 1B and 1C). However, a malignant lesion could not be ruled out. One month after the initial examination, laparotomy was performed. The uterus had been surgically removed. Residual ovaries and fallopian tubes appeared normal. A soft mass measuring approximately $80 \times 88 \mathrm{~mm}$ in size was present in
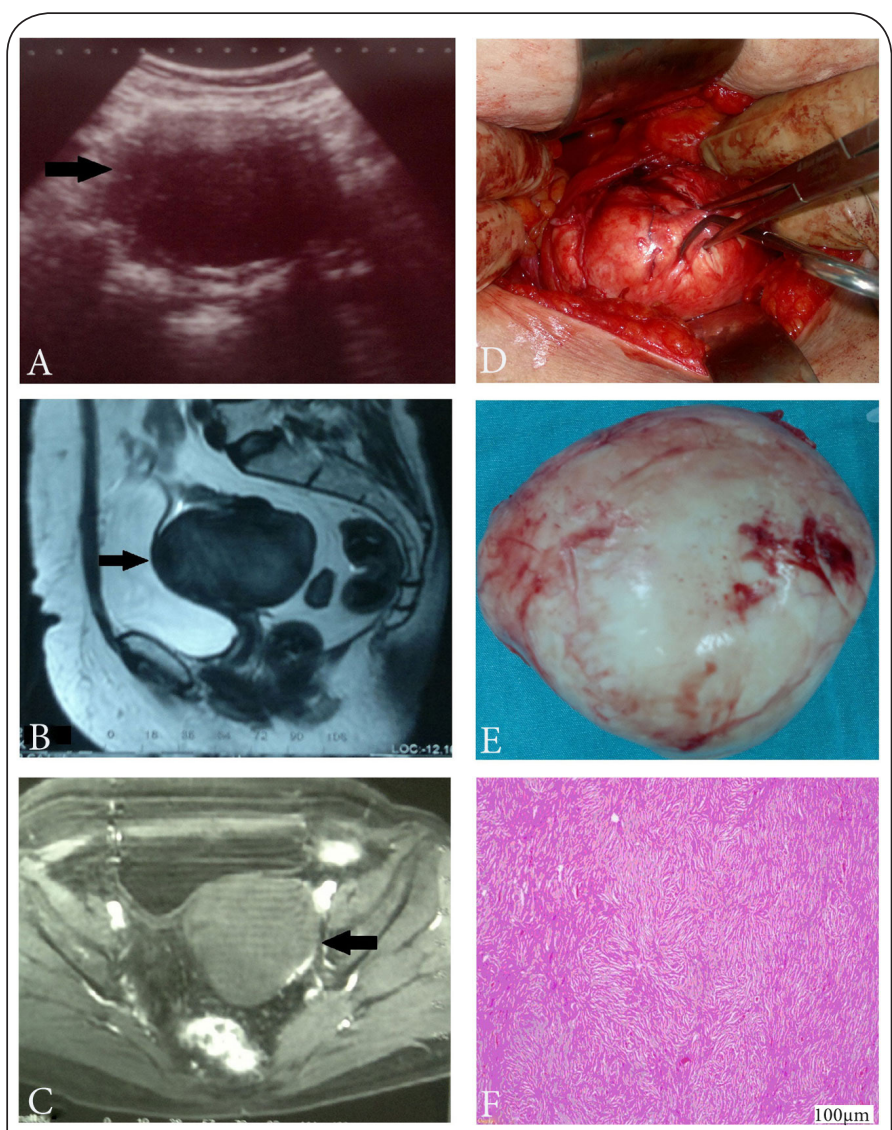

Figure 1. Ultrasonographic (A), magnetic resonance imaging $(\mathbf{B}, \mathbf{C})$, intraoperative view of fibroma (D,E). Pathologic image of fibroma (F): Intersecting bundles of small, thin spindle cells in a collagenous background. There was no cellular atypia and mitotic figures (hematoxylineosin, magnification 40). 
Akpak et al. Pathology Discovery 2014,

the retroperitoneal space. During surgery, it was noticed that the mass lesion tightly adhered to the retroperitoneum and was separate from the ovaries and fallopian tubes (Figure 1D). The frozen section procedure of the mass was performed. It was reported benign mass which had no atypia and mitotic activity. The tumor was resected without complications. Postoperative routine histopathological examination demonstrated fibroma. A 80x80 mm, circumscribed, whitegray, nodular tumor was seen macroscopically (Figure 1E). Microscopically, there were intersecting bundles of small, thin spindle cells in a collagenous background. There was no cellular atypia and mitotic figures (Figure 1F). The patient had a normal postoperative course and was discharged 2 days later.

Benign retroperitoneal tumors represent about $25 \%$ of all retroperitoneal neoplasm. This reported case represents a retroperitoneal tumor of slow growth and benign clinical course [2]. Retroperitoneal fibromas may be confused with other retroperitoneal and adnexial tumors. The management of this lesion should be the excision of the fibromas leaving only the normal appearing tissues. The risk of recurrence requires periodic follow-up (ultrasound pelvic evaluation) [3].

\section{Competing interests}

The authors declare that they have no competing interests.

\section{Authors' contributions}

\begin{tabular}{|l|c|c|c|c|c|}
\hline Authors' contributions & YA & OD & IG & NK & VA \\
\hline Research concept and design & $\checkmark$ & -- & $\checkmark$ & -- & $\checkmark$ \\
\hline Collection and/or assembly of data & $\checkmark$ & $\checkmark$ & $\checkmark$ & $\checkmark$ & -- \\
\hline Data analysis and interpretation & $\checkmark$ & $\checkmark$ & $\checkmark$ & $\checkmark$ & -- \\
\hline Writing the article & $\checkmark$ & $\checkmark$ & -- & -- & -- \\
\hline Critical revision of the article & $\checkmark$ & -- & $\checkmark$ & -- & -- \\
\hline Final approval of article & $\checkmark$ & -- & $\checkmark$ & -- & $\checkmark$ \\
\hline
\end{tabular}

\section{Publication history}

Editor: Takuji Tanaka, Gifu University, Japan.

EIC: Markus H. Frank, Harvard Medical School, USA.

Received: 27-Apr-2014 Final Revised: 14-May-2014

Accepted: 22-May-2014 Published: 30-May-2014

\section{References}

1. Bassi G, Velasquez SB, Orozco RF and Garcia-Gallont R. An incidental retroperitoneal solitary fibrous tumor. Pathol Discov. 2014; 2:1. | Article

2. Illuminati G, Bertagni A, Montesano G, Soda G, Baiocchini A, Melis M and Vietri F. Calcified retroperitoneal fibroma. Eur Rev Med Pharmacol Sci. 1997; 1:125-9. I PubMed

3. Seracchioli R, Bagnoli A, Colombo FM, Missiroli S and Venturoli S. Conservative treatment of recurrent ovarian fibromas in a young patient affected by Gorlin syndrome. Hum Reprod. 2001; 16:1261-3. I Article I PubMed

\section{Citation:}

Akpak YK, Dandin O, Gun I, Kaya N and Atay V. A rare cause of benign retroperitoneal mass mimicking adnexial malignancy in a postmenopausal woman: retroperitoneal fibroma. Pathol Discov. 2014; 2:4. http://dx.doi.org/10.7243/2052-7896-2-4 